\title{
COMPARAÇÃO ENTRE A COMPOSIÇÃO NUTRICIONAL DOS RÓTULOS E AS ANÁLISES LABORATORIAIS DE QUEIJOS MINAS FRESCAL (TRADICIONAL E LIGHT)
}

\section{Comparison between the nutritional composition of the labels and the laboratory analyses of minas frescal cheeses (tradicional and light)}

\author{
Luciana Elisa Oliveira ${ }^{l}$, Cassiano Oliveira da Silva ${ }^{l}$, Grazieli Benedetti Pascoal ${ }^{*}$
}

\begin{abstract}
RESUMO
O queijo minas frescal pode ser apresentado nas formas tradicional ou light e são regulamentados por legislação específica. As informações apresentadas nos rótulos devem ser fidedignas e de qualidade, possibilitando ao consumidor conhecer a quantidade de nutrientes e manter sua saúde. O objetivo do estudo foi avaliar e comparar a composição nutricional declarada nos rótulos com a obtida em análises laboratoriais de queijos minas frescal (tradicional e light) comercializados em Uberlândia, MG. Foram adquiridas seis marcas de queijos minas frescal (duas marcas tradicionais e quatro marcas light), em dois lotes distintos, as quais foram analisadas em triplicata. O teor de lipídios dos queijos minas frescal light não foi estatisticamente diferente $(\mathrm{p}>0,05)$ dos queijos tradicionais e, dessa forma, os queijos minas frescal light estavam em inconformidade com a legislação brasileira vigente (Portaria 27/98). Os resultados mostraram que todas as marcas analisadas sofreram variação no valor energético, no teor de lipídios e/ou teor de proteínas maior que 20\%, estando em inconformidade com a legislação brasileira vigente (RDC 360/03). Além disso, somente três marcas analisadas apresentaram os teores de lipídios estabelecidos pela legislação. Os resultados obtidos sugerem a necessidade de maior rigor durante o processo de fabricação de queijos minas frescal e também de maior fiscalização por parte das agências reguladoras, com o objetivo de assegurar a qualidade das informações disponibilizadas nos rótulos, bem como a segurança alimentar e nutricional da população.
\end{abstract}

Palavras-chave: rotulagem; composição nutricional; segurança alimentar.

1 Universidade Federal de Uberlândia, Faculdade de Medicina, Av. Pará, 1720, Bloco 2U, sala 20, Campus Umuarama, 38.405-320, Uberlândia, MG, Brasil. E-mail: grazi_nutri@yahoo.com.br

* Autor para correspondência

Recebido / Received: 01/05/2014

Aprovado / Approved: 12/06/2014

Rev. Inst. Laticínios Cândido Tostes, Juiz de Fora, v. 69, n. 4, p. 280-288, jul./ago., 2014 


\begin{abstract}
Minas Frescal cheese can be presented in traditional or light forms and is regulated by specific legislation. The information presented on labels must be reliable and have quality, allowing consumers to know the amount of nutrients and to maintain their health. The aim of the study was to evaluate and compare the nutritional composition stated on the labels with that obtained by the laboratory analyzes of Minas Frescal cheeses (traditional and light) sold in Uberlândia, MG. Six brands of Minas Frescal cheeses (two traditional and four light) were acquired in two separate lots, which were analyzed in triplicate. The fat content of the light Minas Frescal cheeses was not statistically different $(p>0.05)$ from the traditional one and, then, the light Minas Frescal cheese were in disagreement with Brazilian Federal Decree (27/98). The results showed all brands suffered variation in energy, fat and/ or protein content greater than $20 \%$ and were in disagreement with the RDC 360/03. Moreover, only three brands tested showed levels of fat established by legislation. The results suggest the need for greater rigor in the manufacturing process of Minas Frescal cheeses, as well as increased inspection by regulatory agencies, in order to ensure the quality of the information provided on labels and the food and nutritional security of the population.
\end{abstract}

Keywords: labeling; nutritional composition; food safety.

\section{INTRODUÇÃO}

Atualmente, a população está mais consciente com relação à sua saúde e observase que tem crescido a preocupação com a adoção de um estilo de vida mais saudável. Tal comportamento tem despertado a indústria a produzir alimentos mais saudáveis, acompanhando, desta forma, a tendência dos consumidores pela busca de alimentos mais nutritivos e com teores reduzidos de gorduras e energia (CUNHA et al, 2002; ZARBIELLI et al., 2004). Dentro deste contexto, houve um aumento da oferta de produtos light, os quais são classificados como alimentos convencionais e regulamentados pela Agência Nacional de Vigilância Sanitária (ANVISA) do Ministério da Saúde (MS) (ANVISA, 1998).

Por definição, o termo "light" deve ser utilizado quando o valor energético e/ou o teor de determinados nutrientes (açúcares, gorduras totais, gorduras saturadas, colesterol e sódio) forem reduzidos em, no mínimo, $25 \%$ quando comparado a um produto tradicional ou similar. Portanto, este alimento satisfaz as condições de declaração de atributos comparativos (ANVISA, 1998; BRASIL, 2012). Os produtos light apresentam somente teores de nutrientes e/ou energia reduzidos e, portanto, tais alimentos não têm finalidade de atender necessidades dietoterápicas específicas.

O queijo minas frescal é um produto popular no Brasil, sendo frequentemente consumido pela população em geral, e tem ganhado novas formulações como, por exemplo, o queijo minas frescal light (ZARBIELLI et al, 2004; SANGALETTI et al, 2009). A produção de queijo minas frescal tem crescido nas últimas décadas e encontrase, atualmente, em terceiro lugar na lista dos queijos mais produzidos no Brasil, ficando atrás somente dos tipos muçarela e prato (CUNHA et al, 2002; ULIANA; ROSA, 2009).

O queijo minas frescal é um alimento regulamentado pelo Ministério da Agricultura, Pecuária e Abastecimento (MAPA) pela Portaria $n^{\circ} 352$ de 04 de setembro de 1997 
complementada pela Instrução Normativa $n^{\circ} 4$, de 01 de março de 2004. Por definição, queijo minas frescal consiste em um produto fresco "obtido por coagulação enzimática do leite com coalho e/ou outras enzimas coagulantes apropriadas, complementada ou não com ação de bactérias lácticas específicas" (BRASIL, 1997a). A Portaria $n^{\circ} 352 / 97$ classifica o queijo minas frescal tradicional como semigordo, apresentando entre 25,0 e $44,9 \%$ de matéria gorda no extrato seco; e de muita alta umidade, apresentando umidade superior a 55\% (BRASIL, 1997a; 2004).

A aquisição de informações corretas sobre o conteúdo de nutrientes dos alimentos configura-se uma questão de segurança alimentar nutricional (SAN), que consiste "na realização do direito de todos ao acesso regular e permanente a alimentos de qualidade, em quantidade suficiente, sem comprometer o acesso a outras necessidades essenciais, tendo como base práticas alimentares promotoras de saúde que respeitem a diversidade cultural e que sejam ambiental, cultural, econômica e socialmente sustentáveis" (BRASIL, 2006). Dessa forma, é importante a obtenção de informações nutricionais adequadas sobre os produtos de uma forma geral (CÂMARA et al, 2008).

No Brasil, a rotulagem de alimentos está regulamentada pela ANVISA por meio das Resoluções da Diretoria Colegiada (RDC) $\mathrm{n}^{\mathrm{o}} 259$ de 20 de setembro de 2002, $\mathrm{n}^{\mathrm{o}} 360$ de 23 de dezembro de 2003, no 359 de 23 de dezembro de 2003. Particularmente, os alimentos light foram regulamentos pela

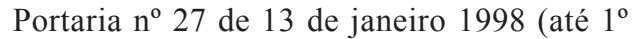
de Janeiro de 2014) e, atualmente, são regulamentados pela RDC 54/12 (ANVISA, 2012). Ademais, os alimentos devem apresentar rótulos apropriados, respeitando ainda o Código de Defesa do Consumidor, o qual estabelece em seu artigo $6^{\circ}$ que a informação adequada e clara sobre os diferentes produtos e serviços é um direito básico dos consumidores (BRASIL, 1990).
A rotulagem de alimentos possibilita à população adquirir informações sobre os tipos e as quantidades de nutrientes. Dessa forma, o rótulo pode ser considerado uma ferramenta educativa e eficaz, uma vez que o consumidor pode selecionar alimentos baseando-se em sua informação nutricional e esta prática auxilia na prevenção de doenças e/ou na manutenção da sua saúde. No entanto, para tal finalidade, é imprescindível a fidedignidade das informações veiculadas nos rótulos (SILVA; FERREIRA, 2010).

Diante do exposto, os objetivos do presente trabalho foram avaliar e comparar a composição nutricional declarada nos rótulos com a obtida em análises laboratoriais de queijos minas frescal (tradicional e light) comercializados em Uberlândia, Minas Gerais; e verificar se os rótulos de queijos minas frescal light estavam de acordo com a legislação brasileira vigente.

\section{MATERIAL E MÉTODOS}

O presente estudo investigou os queijos minas frescal (tradicional e light) que apresentavam registro no Serviço de Inspeção Federal (SIF) do MAPA e que foram obtidos em estabelecimentos exclusivamente varejistas localizados em Uberlândia, Minas Gerais.

Foram analisadas duas marcas (A e B) de queijos minas frescal tradicional e quatro marcas (C, D, E e F) de queijo minas frescal light, em dois lotes distintos. As amostras foram adquiridas em 2012, com intervalo de aproximadamente seis meses, e a coleta dos alimentos ocorreu durante a validade exclusiva da Portaria 27/98 (BRASIL, 1998) e antes da publicação da RDC 54/12 (BRASIL, 2012).

Foram feitas duas tomadas de ensaio (lote 1 e lote 2), nas quais foram adquiridas amostras de queijo minas frescal tradicional e de queijo minas frescal light, que foram analisadas em triplicata $(n=3)$. Dessa forma, o delineamento do presente estudo foi consistido por: 2 tomadas de ensaio (lotes 
1 e 2) x 2 tratamentos (queijo minas frescal tradicional e light) × 6 marcas $\times 1$ unidade amostral x 3 análises (ou repetições).

Para a determinação da composição centesimal (umidade, proteínas, lipídios e cinzas), as amostras de queijos minas frescal (tradicional e light) foram armazenadas a $-18^{\circ} \mathrm{C}$, até realização das análises. A análise da composição centesimal foi realizada de acordo com os métodos oficiais propostos pela Association of Official Analytical Chemists (AOAC, 2012) e pelo Instituto Adolfo Lutz (2008). O fator de conversão para o cálculo das proteínas foi de 6,38, segundo a RDC 360/03 (ANVISA, 2003b). Os carboidratos (CHO) totais foram calculados da seguinte forma: $\%$ CHO totais $=100 \%-[\%$ umidade + \%proteínas + \%lipídios + \%cinzas] (ANVISA, $2003 b$ ). O valor energético total (VET) foi obtido pela seguinte fórmula: $\mathrm{VET}=($ carboidratos $\mathrm{x} 4)+$ (proteínas x 4) + (lipídios x 9) (BRASIL, 2003b).

A análise estatística foi realizada com o auxílio do software SAEG versão 9.1 e consistiu na obtenção das médias e do desvio-padrão. Para comparação das médias gerais entre os tipos de queijos (tradicional e light) foi utilizado o teste t não pareado, considerando o nível de significância de 5\%.

\section{RESULTADOS E DISCUSSÃO}

A Tabela 1 apresenta a composição centesimal (\% na base úmida) e o valor energético (kcal/100g) dos queijos minas frescal tradicional e light comercializados em Uberlândia, Minas Gerais. Comparando os dois tipos de queijos (tradicional e light), de acordo com as médias gerais, observaramse que os teores de umidade, proteínas, carboidratos totais e o valor energético foram estatisticamente diferentes $(\mathrm{p}<0,05)$. Contudo, os teores de cinzas e lipídios dos queijos minas frescal (tradicional e light) não foram estatisticamente diferentes $(\mathrm{p}>0,05)$.

$\mathrm{O}$ valor energético médio dos queijos minas frescal light $(181,3 \pm 23,8 \mathrm{kcal} / 100 \mathrm{~g})$ foi apenas 17\% menor (diferença de 37,1 $\mathrm{kcal} / 100 \mathrm{~g}$ ) que o valor energético médio dos queijos minas frescal tradicionais $(218,4 \pm 19,3$ $\mathrm{kcal} / 100 \mathrm{~g}$ ). Adicionalmente, o teor médio de lipídios dos queijos minas frescal light $(12,8 \pm 3,3 \%)$ sofreu redução de apenas 1,5\% (diferença de 0,2g lipídios/100g) quando comparado ao teor médio de lipídios dos queijos minas frescal tradicionais $(13,0 \pm 3,0 \%)$ (Tabela 1). Dessa forma, de acordo com os resultados gerais, as amostras de queijos minas frescal light estavam em inconformidade com a legislação brasileira vigente (Portaria 27/98), que preconizava a redução mínima de $25 \%$ de energia (e diferença maior que $40 \mathrm{kcal} / 100 \mathrm{~g})$ e/ou redução mínima de $25 \%$ de gorduras (e diferença maior que $3 \mathrm{~g}$ gorduras/100g) (ANVISA, 1998).

Entretanto, analisando individualmente cada marca de queijo minas frescal light (C, D, E e F), em comparação aos valores médios dos queijos minas frescal tradicionais, verificou-se que apenas a marca $\mathrm{D}$ satisfez os critérios estabelecidos pela Portaria 27/98 (ANVISA, 1998).

Corroborando com o presente estudo, Silva; Ferreira (2010), ao analisar quatro marcas de queijo minas frescal tradicional e três marcas de queijo minas frescal light, provenientes da cidade de Campos dos Goytacazes (Rio de Janeiro), observaram que nenhuma das amostras de queijo light apresentava teor de gordura compatível com a legislação para que pudessem receber essa denominação.

De acordo com a Tabela 2, o valor energético e os teores de lipídios e de proteínas declarados no rótulo da marca A apresentaram variação maior que $20 \%$ quando comparados com os valores obtidos em laboratório. $\mathrm{O}$ valor energético e o conteúdo de proteína da marca B apresentaram variação aceitável pela legislação vigente, contudo seu teor de lipídios sofreu variação maior que 20\% quando comparados aos valores laboratoriais. A marca $\mathrm{C}$ apresentou variação no valor energético e 
no teor de lipídios aceitável de acordo com a legislação, porém o conteúdo de proteína variou $66,7 \%$, estando em não conformidade com a RDC 360/03. A marca D apresentou variação no valor energético e conteúdo de lipídios superior a 20\%, entretanto, o conteúdo de proteína declarado no rótulo variou $16,3 \%$, quando comparado com valores laboratoriais. As marcas E e F apresentaram variação aceitável no valor energético, porém os teores lipídios e de proteínas sofreram variação maior que os $20 \%$ preconizados pela RDC $360 / 03$, quando comparados aos valores laboratoriais (ANVISA, 2003b).

Vale elucidar, sucintamente, que determinadas marcas de queijos minas frescal (tradicional e light) apresentaram uma variação no conteúdo de nutrientes acima do estabelecido pela legislação ( $\pm 20 \%$; RDC 360/03) (ANVISA, 2003b), a saber: quatro marcas (do total de seis) apresentaram variação no conteúdo de proteínas; cinco marcas (do total de seis) no conteúdo de lipídios; e duas marcas (do total de seis) no valor energético. Estes resultados foram preocupantes, visto que poderiam afetar diretamente aqueles pacientes que necessitam de um controle rigoroso de sua dieta, como, por exemplo, indivíduos portadores de alguma doença renal (CANO et al, 2006), de doenças cardiovasculares ou que precisam perder peso. Diante do exposto, é extremamente importante que os dados de composição de alimentos disponibilizados em rótulos sejam de qualidade e fidedignos para que os profissionais de saúde possam orientar a população de maneira adequada.

Explorando ainda a Tabela 2, nenhuma das marcas analisadas (A, B, C, D, E e F) apresentou-se em conformidade com a legislação vigente, pois as marcas apresentavam variação muito superior ao preconizado em legislação ( $\pm 20 \%$; RDC 360/03, ANVISA, 2003b) para, pelo menos, um dos itens analisados (valor energético, lipídios e proteínas).

Os resultados da presente pesquisa corroboraram com Silva; Ferreira (2010), que analisaram quatro marcas de queijo minas frescal tradicional, três marcas de queijos minas frescal light e cinco marcas de queijo ricota. Silva; Ferreira (2010) encontraram inconformidades frente à legislação vigente

Tabela 1 - Composição centesimal (\% na base úmida) e valor energético (kcal/100g) de queijos minas frescal (tradicional e light), comercializados em Uberlândia, Minas Gerais ${ }^{1}$

\begin{tabular}{ccccccc}
\hline $\begin{array}{c}\text { Marca do } \\
\text { Alimento }\end{array}$ & $\begin{array}{c}\text { Umidade } \\
(\%)\end{array}$ & $\begin{array}{c}\text { Proteínas } \\
(\%)\end{array}$ & $\begin{array}{c}\text { Cinzas } \\
(\%)\end{array}$ & $\begin{array}{c}\text { Lipídios } \\
(\%)\end{array}$ & $\begin{array}{c}\text { Carboidratos } \\
\text { totais } \\
(\%)\end{array}$ & $\begin{array}{c}\text { Valor } \\
\text { energético } \\
(\mathrm{kcal} / 100 \mathrm{~g})\end{array}$ \\
\hline \multicolumn{7}{c}{ Queijo Minas Frescal Tradicional } \\
\hline A & $62,8 \pm 3,5$ & $12,4 \pm 1,4$ & $1,4 \pm 0,4$ & $15,2 \pm 1,7$ & $8,2 \pm 1,6$ & $219,8 \pm 21,2$ \\
B & $56,0 \pm 2,8$ & $17,0 \pm 1,6$ & $3,1 \pm 0,6$ & $10,7 \pm 2,2$ & $13,2 \pm 3,0$ & $217,0 \pm 19,0$ \\
Média & $59,4 \pm 4,6^{\mathrm{a}}$ & $14,7 \pm 2,8^{\mathrm{a}}$ & $2,2 \pm 1,0^{\mathrm{a}}$ & $13,0 \pm 3,0^{\mathrm{a}}$ & $10,7 \pm 3,5^{\mathrm{a}}$ & $218,4 \pm 19,3^{\mathrm{a}}$ \\
\hline \multicolumn{7}{c}{ Queijo Minas Frescal Light } \\
\hline C & $71,1 \pm 0,5$ & $9,6 \pm 0,8$ & $1,1 \pm 0,3$ & $13,2 \pm 0,8$ & $4,9 \pm 0,5$ & $176,0 \pm 5,6$ \\
D & $68,2 \pm 1,8$ & $17,2 \pm 0,9$ & $1,7 \pm 0,6$ & $9,0 \pm 2,6$ & $3,8 \pm 1,9$ & $165,0 \pm 21,2$ \\
E & $70,2 \pm 1,1$ & $11,1 \pm 1,2$ & $2,2 \pm 0,4$ & $14,2 \pm 1,9$ & $2,3 \pm 1,4$ & $181,3 \pm 14,3$ \\
F & $66,1 \pm 4,2$ & $11,5 \pm 0,5$ & $2,0 \pm 0,2$ & $14,9 \pm 3,8$ & $5,6 \pm 3,8$ & $202,0 \pm 31,0$ \\
Média & $68,9 \pm 3,0^{\mathrm{b}}$ & $12,5 \pm 3,1^{\mathrm{b}}$ & $1,7 \pm 0,6^{\mathrm{a}}$ & $12,8 \pm 3,3^{\mathrm{a}}$ & $4,1 \pm 2,5^{\mathrm{b}}$ & $181,3 \pm 23,8^{\mathrm{b}}$ \\
\hline
\end{tabular}

1 Valores médios laboratoriais (considerando os dois lotes); Letras diferentes na mesma coluna significam diferença estatística $(\mathrm{p}<0,05)$. 
(RDC 360/03), visto que 92\% das marcas destes tipos de queijos apresentaram margem de erro superior a $20 \%$ para alguns nutrientes (lipídios, proteínas e sódio).

Resultados semelhantes aos do presente estudo foram obtidos em uma pesquisa realizada em 2013 pelo Instituto Brasileiro de Defesa do Consumidor (IDEC), o qual analisou 25 marcas de queijos minas frescal, sendo 16 marcas de queijos tradicionais e nove marcas de queijos light. O IDEC verificou a quantidade de proteínas, gorduras (totais, saturadas e insaturadas) e sódio presentes nas amostras e os valores obtidos foram comparados com os declarados nos rótulos dos produtos. Os resultados mostraram que todas as amostras informaram erroneamente a quantidade de, pelo menos, um destes nutrientes. (IDEC, 2013).

Câmara et al. (2008) também apontaram um grande número de inadequações nas informações nutricionais presentes nos rótulos dos produtos, frente à legislação brasileira específica.

Segundo a ANVISA, a composição nutricional dos produtos pode ser calculada a partir de tabelas de composição de alimentos, e vale ressaltar que somente é obrigatória a realização de análises físico-químicas quando houver a presença de gordura trans nos alimentos e este dado não estiver disponível em tabelas de composição de alimentos (ANVISA, 2005). O grande número de inconformidades presentes nos rótulos dos produtos se deve ao modo como a composição nutricional dos alimentos industrializados é, na maioria das vezes, calculada, pois cada indústria terá preferência por determinada tabela. Ademais, alguns alimentos não estão presentes em tabelas brasileiras de composição de alimentos e, dessa forma, o conteúdo de nutrientes apresentado no rótulo do produto poderá não corresponder à composição real do alimento.

A Tabela 3 apresenta a classificação dos queijos minas frescal, segundo o teor de lipídios no extrato seco. De acordo com a Portaria $n^{\circ}$ 352/97 do MAPA(BRASIL, 1997a), o queijo minas frescal é classificado como semi-gordo e deve conter entre 25,0 e $44,9 \%$ de lipídios no extrato seco. Já a classificação do queijo minas frescal light dependerá do teor de lipídios da versão tradicional, usada como referência. Dessa forma, duas classificações são possíveis: o queijo minas frescal light poderá ser magro $(10,0 \%$ a $24,9 \%$ de lipídios no extrato seco) ou semi-gordo $(25,0 \%$ a $44,9 \%$ de lipídios no extrato seco).

Entretanto, os resultados do presente estudo apontam que apenas três marcas (das seis analisadas) de queijos minas frescal (tradicional e light) apresentaram-se dentro do valor de lipídios estabelecido por BRASIL (1997a), particularmente a Portaria $n^{\circ} 352 / 97$. Vale ressaltar que entre os queijos minas frescal light, duas marcas (de quatro analisadas) foram classificadas como queijo gordo, apresentando o mesmo conteúdo de lipídios presente no queijo prato (Portaria 358/97) (BRASIL, 1997b). Analisando a Tabela 3, somente de acordo com os valores médios de lipídios, verificouse uma inconsistência, visto que a média de lipídios do queijo minas frescal light foi maior $(\mathrm{p}<0,05)$ que o tradicional. Corroborando com a presente pesquisa, Silva; Ferreira (2010), ao analisar marcas de queijo minas frescal tradicional e light, observaram que $75 \%$ das amostras apresentavam o teor de lipídios estabelecido pelo MAPA, porém duas das sete amostras analisadas foram classificadas como queijo gordo, pois continham mais de $45 \%$ de lipídios no extrato seco.

Em adição, a verificação de adequação dos queijos minas frescal (tradicional e light) da presente pesquisa, frente ao teor de umidade (em \%) do Regulamento Técnico de Identidade e Qualidade (RTIQ) de queijos (Portaria n ${ }^{\circ}$ 146/96, BRASIL, 1996), indicou que a classificação deles estava em conformidade com a legislação vigente, visto que todas as marcas apresentaram um teor 
de umidade maior que 55\%. Dessa forma, o teor médio de umidade, obtido no presente estudo, classificou os queijos minas frescal (tradicional e light) como sendo de "muita alta umidade".

\section{CONCLUSÕES}

A comparação entre os dados apresentados na rotulagem de queijos minas frescal (tradicional e light) e os dados das análises da composição nutricional realizadas em laboratório demonstra-se preocupante, pois existem diferenças substanciais entre ambos. $\mathrm{O}$ não atendimento à legislação brasileira vigente, por parte dos fabricantes de queijos minas frescal, pode evidenciar a pouca eficiência no controle de qualidade destes produtos.

Os resultados sugerem que é necessário maior rigor durante o processo de fabricação de queijos minas frescal, tanto tradicional

Tabela 2 - Comparação dos valores energéticos (kcal/100g), lipídios totais (\%) e proteínas (\%) apresentados nos rótulos com valores médios laboratoriais de queijos minas frescal (tradicional e light), comercializados em Uberlândia, MG

\begin{tabular}{|c|c|c|c|c|c|c|}
\hline \multirow{2}{*}{$\begin{array}{l}\text { Variáveis } \\
\text { nutricionais }\end{array}$} & \multirow{2}{*}{\multicolumn{2}{|c|}{$\begin{array}{c}\text { Queijo Minas Frescal Tradicional } \\
\text { Marca A Marca B }\end{array}$}} & \multicolumn{4}{|c|}{ Queijo Minas Frescal Light } \\
\hline & & & Marca C & Marca D & Marca E & Marca F \\
\hline $\begin{array}{l}\text { Valor energético } \\
\quad(\mathrm{kcal} / 100 \mathrm{~g}) \\
\text { (dados do rótulo) }\end{array}$ & 266,7 & 220,0 & 206,0 & 226,7 & 150,0 & 170,0 \\
\hline $\begin{array}{c}\text { Valor energético } \\
(\mathrm{kcal} / 100 \mathrm{~g}) \\
{\text { (dados laboratoriais })^{1}}^{1}\end{array}$ & 219,8 & 217,0 & 176,0 & 165,0 & 181,3 & 202,0 \\
\hline $\begin{array}{l}\text { Diferença média } \\
(\mathrm{em} \%)^{2}\end{array}$ & $+21,3$ & $+1,4$ & $+17,0$ & $+37,4$ & $-17,3$ & $-15,8$ \\
\hline $\begin{array}{l}\text { Lipídios totais }(\%) \\
\text { (dados do rótulo) }\end{array}$ & 23,0 & 16,3 & 14,0 & 13,3 & 8,0 & 11,0 \\
\hline $\begin{array}{c}\text { Lipídios totais }(\%) \\
\text { (dados } \\
\text { laboratoriais) }\end{array}$ & 15,2 & 10,7 & 13,2 & 9,0 & 14,2 & 14,9 \\
\hline $\begin{array}{l}\text { Diferença média } \\
(\mathrm{em} \%)^{2}\end{array}$ & $+51,3$ & $+52,3$ & $+6,1$ & $+47,8$ & $-43,7$ & $-26,2$ \\
\hline $\begin{array}{c}\text { Proteínas }(\%) \\
\text { (dados do rótulo) }\end{array}$ & 25,0 & 15,0 & 16,0 & 20,0 & 19,4 & 17,7 \\
\hline $\begin{array}{c}\text { Proteínas }(\%) \\
\text { (dados laboratoriais) }\end{array}$ & 12,4 & 17,0 & 9,6 & 17,2 & 11,1 & 11,5 \\
\hline $\begin{array}{l}\text { Diferença média } \\
\quad(\text { em } \%)^{2}\end{array}$ & $+101,6$ & $-11,8$ & $+66,7$ & $+16,3$ & $+74,8$ & $+53,9$ \\
\hline
\end{tabular}

O sinal (+) significa a porcentagem que o teor declarado no rótulo do produto é maior que o valor obtido em laboratório, ao passo que o sinal (-) indica a porcentagem que o teor declarado no rótulo do produto é menor que o valor obtido em laboratório. 1 Valor energético médio dos Lotes 1 e 2: (teor médio de proteínas x 4 kcal) + (teor médio de carboidratos totais x 4 kcal) + (teor médio de lipídios x 9 kcal). 2 Diferença média (em \%) = [(valor do rótulo - valor médio obtido em laboratório)/valor médio obtido em laboratório] x 100. 
quanto light, e maior fiscalização por parte das agências reguladoras, com o objetivo de assegurar o padrão de identidade e qualidade e a fidedignidade das informações disponibilizadas nos rótulos, previstos na legislação brasileira que regula estes produtos. Em adição, é importante que os produtos ofereçam em seus rótulos informações corretas e seguras para os consumidores, com o intuito de garantir a segurança alimentar e nutricional da população.

\section{REFERENCIAS}

AGÊNCIA NACIONAL DE VIGILÂNCIA SANITÁRIA (ANVISA) Portaria ${ }^{\circ} 27,13$ de janeiro de 1998. Regulamento Técnico referente à Informação Nutricional Complementar (declarações relacionadas ao conteúdo de nutrientes), constantes do anexo desta Portaria. Diário Oficial da República do Brasil, Brasília,16 jan. 1998.

AGÊNCIA NACIONAL DE VIGILÂNCIA SANITÁRIA (ANVISA). Resolução RDC n ${ }^{\circ} 54$, de 12 de novembro de 2012. Dispõe sobre regulamento técnico sobre informação nutricional complementar. Diário Oficial da República do Brasil, Brasília, 13 nov. 2012.

AGÊNCIA NACIONAL DE VIGILÂNCIA SANITÁRIA (ANVISA). Resolução RDC n 259 , de 20 de setembro de 2002 alterada pela Resolução RDC $\mathrm{n}^{\circ} 123$, de 13 de maio de 2004 e complementada pela resolução RDC $\mathrm{n}^{\circ} 163$, de 17 de agosto de 2006. Aprova o Regulamento Técnico sobre Rotulagem de Alimentos Embalados. Diário Oficial da República Federativa do Brasil, Brasília, 23 set. 2002.

AGÊNCIA NACIONAL DE VIGILÂNCIA SANITÁRIA (ANVISA). Resolução RDC n 359, de 23 de dezembro de 2003. Aprova Regulamento Técnico de Porções de Alimentos Embalados para Fins de Rotulagem Nutricional. Diário Oficial da República Federativa do Brasil, Brasília, 26 dez. 2003a.

AGÊNCIA NACIONAL DE VIGILÂNCIA SANITÁRIA (ANVISA) Resolução RDC n 360, de

Tabela 3 - Classificação e adequação dos queijos minas frescal (tradicional e light), segundo o teor de lipídios (\% no extrato seco), comercializados em Uberlândia, MG

\begin{tabular}{cccc}
\hline $\begin{array}{c}\text { Marca } \\
\text { do } \\
\text { Alimento }\end{array}$ & $\begin{array}{c}\text { Lipídios } \\
\%\end{array}$ & $\begin{array}{c}\text { Classificação dos } \\
\text { queijos minas frescal } \\
\text { segundo o RTIQ* }\end{array}$ & $\begin{array}{c}\text { Adequação } \\
\text { dos queijos } \\
\text { minas frescal** }\end{array}$ \\
\hline \multicolumn{4}{c}{ Queijo Minas Frescal Tradicional } \\
A & $41,0 \pm 3,3$ & Semi-gordo \\
B & $24,4 \pm 5,1$ & $\begin{array}{c}\text { Magro } \\
\text { Fédia }\end{array}$ & Fora do padrão legal \\
Semi-gordo & Dentro do padrão legal \\
\hline C & $42,7 \pm 9,6^{\text {a }}$ & Queijo Minas Frescal Light \\
D & $28,1 \pm 7,0$ & Gordo \\
E & $47,6 \pm 5,4$ & Semi-gordo & Fora do padrão legal \\
F & $44,0 \pm 11,1$ & Gordo & Fora do padrão legal \\
Média & $41,3 \pm 10,4^{\text {b }}$ & Semi-gordo & Dentro do padrão legal \\
\hline
\end{tabular}

n=3 para o lote 1 e lote 2. *Classificação do produto segundo o Regulamento Técnico de Identidade e Qualidade (RTIQ) de queijos da Portaria ${ }^{\circ}$ 146/96 do MAPA (BRASIL, 1996). **Para a análise da adequação (dentro ou fora do padrão legal) dos queijos minas frescal (tradicional e light), foi utilizada a Portaria 352/97 do MAPA (BRASIL, 1997a). 'Valores médios laboratoriais (considerando os dois lotes); Letras diferentes na coluna significam diferença estatística, $\mathrm{p}<0,05$. 
23 de dezembro de 2003. Aprova Regulamento Técnico sobre Rotulagem Nutricional de Alimentos Embalados, tornando obrigatória a rotulagem nutricional. Diário Oficial da República do Brasil, Brasília, 26 dez. 2003b.

AGÊNCIA NACIONAL DE VIGILÂNCIA SANITÁRIA (ANVISA). Rotulagem Nutricional Obrigatória: manual de orientação às indústrias de alimentos. $2^{\mathrm{a}}$ versão. Brasília: Ministério da Saúde, Agência Nacional de Vigilância Sanitária/ Universidade de Brasília, 2005. 44p.

ASSOCIATION OF OFFICIAL ANALYTICAL CHEMISTS (AOAC). Official methods of analysis of the AOAC International. $19^{\text {th }}$ ed. Washington: AOAC, 2012.

BRASIL. Lei $n^{0} 8.078$, de 11 de setembro de 1990. Dispõe sobre a proteção do consumidor e dá outras providências. Diário Oficial da República Federativa do Brasil, Brasília, 12 set. 1990.

BRASIL. Lei n ${ }^{\circ} 11.346$, de 15 de setembro de 2006. Cria o Sistema Nacional de Segurança Alimentar e Nutricional - SISAN com vistas em assegurar o direito humano à alimentação adequada e dá outras providências. Diário Oficial da República Federativa do Brasil, Brasília, 18 set. 2006.

BRASIL. Ministério da Agricultura, Pecuária e Abastecimento. Portaria $n^{\circ} 146$, de 7 de março de 1996. Aprova os regulamentos técnicos de identidade e qualidade dos produtos lácteos. Diário Oficial da República do Brasil, Brasília, 11 mar. 1996. Seção 1, Página 3977.

BRASIL. Ministério da Agricultura, Pecuária e Abastecimento. Portaria $n^{\circ} 352$ de 04 de setembro de 1997. [Aditivos no Regulamento Técnico para Fixação de Identidade e Qualidade do Queijo Minas Frescal]. Instrução Normativa $\mathrm{n}^{\circ} 4$, de 01 de março de 2004. Diário Oficial da República do Brasil, Brasília, 5 mar. 2004.

BRASIL. Ministério da Agricultura, do Abastecimento e da Reforma Agrária. Portaria no 358, de 04 de Setembro de 1997. Aprova o Regulamento Técnico para Fixação de Identidade e Qualidade de Queijo Prato. Diário Oficial da República do
Brasil, Brasília, 08 set. 1997b. Seção 1, Página 19690.

CÂMARA. M. C. C. et al. A produção acadêmica sobre a rotulagem de alimentos no Brasil. Revista Panamericana de Salud Publica, v. 23, n. 1, p. 52-58, 2008.

CUNHA, C. R. et al. Efeito do fator de concentração do retentado, o rendimento de queijo minas frescal de baixo teor de gordura fabricado por ultrafiltração. Ciência e Tecnologia de Alimentos, v. 22, n. 1, p. $76-8,2002$.

CANO, N. et al. ESPEN guidelines on enteral nutrition: adult renal failure. Clinical Nutrition, v. 25, n. 2, p. 295-310, 2006.

INSTITUTO ADOLFO LUTZ. Normas Analíticas do Instituto Adolfo Lutz: Métodos físicoquímicos para análise de alimentos. 4 ed. São Paulo: Instituto Adolfo Lutz, 2008. 1020 p.

INSTITUTO BRASILEIRO DE DEFESA DO CONSUMIDOR (IDEC). O que os olhos não leem o corpo não sente? Disponível em: $<$ http:// www.idec.org.br/em-acao/revista/falsos-magros/ materia/o-que-os-olhos-no-leem-o-corpo-no-sente/ pagina/430 > Acesso em: 15 de nov. 2013.

SANGALETTI, N. et al. Estudo da vida útil de queijo Minas. Ciência e Tecnologia de Alimentos, v. 29, n. 2, p. 262-269, 2009.

SILVA, L. F. M.; FERREIRA, K. S. Avaliação de rotulagem nutricional, composição química e valor energético de queijo minas frescal, queijo minas frescal light e ricota. Revista Alimentos e Nutrição, v. 21, n. 3, p. 437-441, 2010.

ULIANA, G. C.; ROSA, C. S. Avaliação físicoquímica e sensorial de queijos coloniais com adição de extrato hidrossolúvel de soja e farelo de soja. Revista Alimentos e Nutrição, v. 20, n. 3, p. 485-489, 2009.

ZARBIELLI, M. et al. Formulação e caracterização físico-química e sensorial de queijo minas light enriquecido com fonte de ferro. Revista Alimentos e Nutrição, v. 15, n. 3, p. 251-257, 2004. 